\title{
The role of information asymmetry in the choice of entrepreneurial exit routes
}

\author{
Tobias Dehlen, Thomas Zellweger*, Nadine Kammerlander, Frank Halter \\ Center for Family Business, University of St. Gallen, Dufourstrasse 40a, CH-9000 St. Gallen, Switzerland
}

\section{A R T I C L E I N F O}

\section{Article history:}

Received 21 March 2012

Received in revised form 4 October 2012

Accepted 4 October 2012

Available online $\mathrm{xxxx}$

Field Editor: D. Shepherd

Keywords:

Entrepreneurial exit

Exit routes

Succession

Information asymmetry

Emotional attachment

\begin{abstract}
A B S T R A C T
Our quantitative study investigates the determinants of internal versus external exit routes in family firms. Building on information asymmetry theory, we examine how an owner's inferior knowledge about the abilities of potential external entrants (in contrast to family internal successors) renders a family internal transfer more likely. This information asymmetry, however, can be mitigated by activities such as owners' screening and transfer candidates' signaling efforts to reveal the candidates' abilities. Our data exhibits a positive effect of signaling and an inverted U-shaped effect of screening on the probability of external exit routes. Firm age, as a driver of emotional attachment, weakens these effects.
\end{abstract}

(c) 2012 Elsevier Inc. All rights reserved.

\section{Executive summary}

The transfer of ownership and management from an incumbent entrepreneur to his or her successor is an important and often studied phenomenon. Prior literature (Wennberg et al., 2011) shows that the choice of exit route is highly influential on the future firm prosperity.

Thus far, we still lack a comprehensive understanding and quantitative evidence about what factors determine to whom the entrepreneur transfers the business. We aim to contribute to filling this gap by studying how economic and non-economic factors independently and interactively affect whether ownership and management of a company are transferred to an intra-family successor or to an external individual.

Building on information asymmetry theory, we first argue that incumbents have an inherent preference for family internal successors because they have superior knowledge about the abilities of those succession candidates as compared to external ones. In consequence, they prefer to hand the business over to an offspring or another relative because they are more confident that these new entrepreneurs will be likely to successfully continue firm operations. We further argue that mechanisms that increase the incumbent's knowledge about external candidates' abilities heighten the probability of a transfer to an external entrepreneur. Important mechanisms to reduce asymmetric information are the candidate's active revelation of his or her abilities ('signaling'), for instance through educational achievements or prior work experience, as well as the incumbent's active search for information on the candidate's abilities ('screening').

\footnotetext{
* Corresponding author. Tel.: +4171224 7100; fax: +4171224 7101.

E-mail address: thomas.zellweger@unisg.ch (T. Zellweger).
} 
T. Dehlen et al. / Journal of Business Venturing $x x x$ (2012) $x x x-x x x$

In a second step, we theorize how non-economic factors, in particular firm age which entails emotional attachment to the firm, affects exit route choices. We lay out how entrepreneurs of older firms develop socioemotional wealth and become increasingly attached to their company and show reluctance to pass the business to an outsider. We hence propose that firm age reduces the probability of an external transfer.

In a final step, we integrate economic and non-economic rationales and discuss how firm age alleviates the effects of signaling as well as screening. In particular, we argue that firm age and emotional attachment induce a status quo bias, which in turn leads to selective cognitive attention and to quality discounts on information on the external candidate's abilities. As a result, the hypothesized effects of education, work experience, and screening are weakened by firm age.

We test our hypotheses based on a sample of 1036 owner-managers of small- and medium-sized Swiss, German and Austrian enterprises, who have recently taken over control of their firm. A logit regression with supplementary graphical interpretation confirms the proposed hypotheses. Additional analyses (e.g., multiple imputation) indicate the robustness of our findings.

The theoretical and empirical findings of this study contribute in particular to three streams of literature. First, we add to entrepreneurial exit literature by showing how elements that characterize the dyadic relationship between incumbent and successor (DeTienne, 2010) impact entrepreneurial exit choices. As one of the first, we apply information asymmetry to explain variance in exit route choices.

Second, we contribute to family business research by providing a more holistic picture on the determinants of family-internal vs. external succession. Instead of considering only emotional factors, we consider economic and non-economic determinants independently as well as in interaction.

Third, we contribute to research on information asymmetry by applying it to a sparsely studied context (incumbent's perspective in entrepreneurial exits). Moreover, our study reveals a 'flip side of the coin' of excessive screening mechanisms. As we argue and empirically show, high levels of screening result in discouragement of the screened individuals and subsequent lower probability of firm transfer to those candidates.

\section{Introduction}

Entrepreneurial exit - the transfer of control over an entrepreneurial firm to one or several individuals or an organization, alternatively the liquidation of the firm - is an important entrepreneurial phenomenon that affects not only the entrepreneur and the firm but also the industry and, in some cases, even the regional economy (DeTienne, 2010). Each firm owner must eventually exit his or her business; however, there are various exit routes to choose from. The choice of a specific exit route influences the future prosperity of the firm. For example, a recent study by Wennberg et al. (2011) on Swedish family firms indicates that family internal successions as compared to external transfers of control are associated with higher likelihood of survival but inferior short- and long-term performance.

Despite these advances in the field, particularly with respect to the performance implications of various exit routes, the determinants of an entrepreneurial owner's choice of a specific exit route still remain largely unexplored (DeTienne and Cardon, 2012). Entrepreneurship scholars have only recently begun to investigate the influence of determining factors such as the owners' entrepreneurial characteristics (DeTienne and Cardon, 2012), their motivations (DeTienne and Chandler, 2010), and their framing (Wennberg et al., 2010) on entrepreneurial owners' exit route decisions. Until now, this stream of research has focused primarily on the incumbent's perspective and has ignored the dyadic setting of firm-transfer processes (DeTienne, 2010; Graebner and Eisenhardt, 2004). Family business scholars, on the other hand, have long emphasized the tendency of owner-managers to pass on their businesses within the family (e.g., Le Breton-Miller et al., 2004; Lee et al., 2003) due to nepotism (Barach et al., 1988; Gersick et al., 1997) and have even included 'transgenerational intention' in the definition of family businesses (Chandler, 1990; Chua et al., 1999; Ward, 1987). In family business research, variance in the choice of exit routes is ascribed primarily to the presence of several individual, relational, financial, and contextual factors that impede the preferred internal succession (De Massis et al., 2008); however, most of the respective studies are either conceptual or qualitative in nature.

Enhancing knowledge of the antecedents of exit route decisions is crucial because such choices fundamentally affect firm performance after the transfer (Wennberg et al., 2011). In this study, we build on information asymmetry theory to explain variance in the exit route decisions of the owner-managers of privately owned firms. Information asymmetry is a theoretical lens that has recently gained substantial attention in the entrepreneurship field (e.g., Dawson, 2011; Wennberg et al., 2011). We therefore follow the emerging stream of family business research that draws on economic-rational explanations to investigate succession processes (e.g., Lee et al., 2003; Royer et al., 2008) by arguing that firm owners are economically motivated to apply measures that reduce information asymmetry which, in turn, affect the owners' exit decisions. However, family business scholars, particularly those who address socioemotional wealth considerations (e.g., Gómez-Mejía et al., 2007), have long emphasized that an owner's attachment to his or her firm is particularly rooted in non-economic reasons, such as legacy concerns, which grow stronger over time (Zellweger et al., 2012). To also account for this perspective, we next investigate how such non-economic rationales affect entrepreneurial exits. In a final step, we examine the interactive effect of economic and non-economic factors.

We thus aim to answer three research questions: (1) How do economic factors, such as signaling and screening that reduce information asymmetries affect the choice of entrepreneurial exit routes? (2) How do non-economic rationales such as firm age, which is a key driver of emotional attachment, affect the choice entrepreneurial exit routes? (3) How do economic and non-economic factors in combination affect the choice of entrepreneurial exit routes?

To answer these questions, we probe survey responses of owner-managers of SMEs in three European countries, who have recently taken over the management and ownership of their firms. 
Our study contributes in several ways to research on entrepreneurial exit, family businesses, and information asymmetry. First, we provide a novel economics-based, so far under-investigated explanation for owners' preference for family internal successions. Second, by studying the effect of measures that reduce information asymmetry between incumbents and their successors, we advance the literature on antecedents of entrepreneurial exit route decisions. Third, this study integrates two important but previously unconnected strands of literature: information asymmetry and research on socioemotional wealth. Considering economic and non-economic factors together makes it possible to draw a more nuanced and holistic picture of the determinants of exit route decisions. Fourth, by investigating simultaneous transfers of ownership and management instead of merely management transitions, this study extends beyond the previous work conducted by family business scholars. Finally, this is, to the best of our knowledge, the first study to quantitatively examine the role of information asymmetry in entrepreneurial exit choices.

\section{Theoretical foundations}

\subsection{Economic rationales: asymmetric information}

The asymmetric information perspective highlights that "information is imperfect, obtaining information can be costly, [and] there are important asymmetries of information" (Stiglitz, 2000, p.1441). Information asymmetry occurs when the knowledge of one contracting party is inferior to that of the other party regarding the counterparty's true intentions and planned activities (Mas-Colell et al., 1995; Spence, 1976) or the quality of exchanged goods (Akerlof, 1970). Examples of the latter include employers who are eager to know a potential employee's abilities prior to the job offer (Stiglitz, 2000), boards that lack sufficient knowledge on the characteristics of firm-external CEO candidates (Zajac, 1990), and investors who want to know the true value of a firm before they acquire it (Capron and Shen, 2007) or invest in it (Cohen and Dean, 2005).

The literature proposes several mechanisms that may be used to overcome information asymmetry. According to the agency literature, information asymmetry regarding intentions and planned activities can be alleviated via contingency or incentive contracting and monitoring (e.g., Fama, 1980; Jensen, 1986; Kreps, 1997; Wiseman and Gómez-Mejía, 1998). Information symmetry regarding the quality of goods exchanged can be reduced via signaling (the active conveyance of information by the knowledgeable party) and/or screening (the active seeking of additional information by the uninformed party) (Carpentier et al., 2010; Janney and Folta, 2003, 2006; Lee and Venkataraman, 2006; Stiglitz, 2000).

In entrepreneurship studies, information asymmetry has recently gained substantial attention and research based on this theoretical perspective has been conducted to investigate the decision-making of private equity firms regarding the acquisition of family firms (Dawson, 2011), the choice of founder vs. non-founder CEOs in firms issuing IPOs (Jain and Tabak, 2008), and entrepreneurial vs. non-entrepreneurial career choices (Lee and Venkataraman, 2006).

\subsubsection{Asymmetric information and entrepreneurial exit decisions}

In general, retiring entrepreneurs can choose among several types of exit routes: liquidation; public quotation; family internal succession; or sale to employees, to an independent party, or to another firm (Birley and Westhead, 1993; DeTienne and Cardon, 2012; Petty, 1997). Among the SMEs that are not liquidated upon the entrepreneur's exit, only a small number is introduced to the stock market (Westhead, 2003). Given our focus on exit routes that involve individual entrepreneurs as incumbents and successors and information asymmetry between those two parties, we henceforth limit our discussion to family internal succession on the one hand and sale to employees (management buy-out; MBO) or independent individuals (management buy-in; MBI) on the other hand, the two latter labeled external succession. As such, our study focuses on the most prominent exit routes within SMEs in Western economies (Howorth et al., 2004).

Asymmetric information is a crucial determinant of entrepreneurial exit routes (Howorth et al., 2004; Scholes et al., 2007) because such transactions are affected by four types of asymmetric information (Halter et al., forthcoming). First, the succession candidate lacks information about the 'quality' of the transaction goods (i.e., the current state of the firm, in particular, its financial soundness). Second, the succession candidate is unaware of the incumbent's intentions and planned post-succession behavior. For example, the potential successor typically does not know whether the former business owner plans to re-open a competing business after closing the deal. Third, the incumbent has inferior information about the successor's abilities (i.e., whether he or she is capable of successfully continuing the business operations). Finally, the incumbent is unable to determine or predict the successor's intentions and post-succession behavior (i.e., whether the successor will comply with contractual and non-contractual agreements related, for example, to the incumbent's opportunity for future involvement in the business and future access to information). Due to this lack of information, each contracting party is likely to assume the worst-case scenario in order to minimize his or her own risk (Akerlof, 1970; Dawson, 2011) and may ultimately refrain from engaging in the transaction. Hence, the four types of information asymmetry between the incumbent and the successor may exacerbate and, in some cases, ultimately hinder entrepreneurial firm transfers.

\subsubsection{Incumbent's information asymmetry on the abilities of successor candidates}

We focus on the incumbent's lack of information about the candidate's abilities because, despite some recent advances, the incumbent's perspective still remains under-investigated (DeTienne, 2010; Graebner, 2009; Graebner and Eisenhardt, 2004). Most entrepreneurship research until now has focused on the successor's perspective (Capron and Shen, 2007; Dawson, 2011) and has thereby neglected the pivotal role of the incumbent who ultimately decides when and to whom he or she will transfer the business.

Recent research shows that private firm owners care about the company's post-succession prosperity and indicates that the outlook for the firm's future affects their exit decisions (Cardon et al., 2005; DeTienne, 2010; Graebner and Eisenhardt, 2004). This 
finding is consistent with family business research that purports the inextricable intertwinement of owner and business and the subsequent concern about the future wellbeing of the organization and its stakeholders (e.g., Chrisman et al., 2003; Howorth et al., 2004; Niedermeyer et al., 2010; Sharma and Manikutty, 2005). We thus expect a firm owner to carefully consider the ability of the potential successor to operate the firm successfully before making an exit decision. In the presence of information asymmetry regarding the candidate's abilities, the firm owner cannot be sure that the potential successor will be able to successfully continue the firm's business operations.

The level of information asymmetry regarding a successor's abilities is profoundly different for family internal as opposed to external candidates (Howorth et al., 2004). Whereas incumbent owners often have limited information about an external candidate's abilities before the succession takes place, they are usually highly informed about the level of education, experience, and ultimately ability of family members. Extensive knowledge and, thus, low information asymmetry regarding the abilities of family internal candidates is based on the long-term intimate relationships that are typical between senior and junior generations. Senior generation family members are able to observe the junior family member's level of knowledge, behavior, and abilities in various contexts, be it in personal and rather private settings, in private conversations about the firm at home or frequently also in part-time employment in different functional departments of the firm. This results in a detailed and comprehensive understanding of the family candidate's abilities. The incumbent possesses first-hand insight not only into the potential successor's level of ability, but also into his or her learning capacity. Thus, the incumbent will have an enhanced understanding of the candidate's potential to operate the firm successfully (Holmstrom, 1982). Just as insurers can learn about contractors' risk profiles or employers can learn about employees' abilities through information accumulation via multiple interactions (Farber and Gibbons, 1996; Palfrey and Spatt, 1985), incumbents have a natural informational advantage in assessing family internal candidates. Similar to board decisions regarding CEO succession (Zhang, 2008), an incumbent's decision regarding the potential succession of a family member "will generally be one in which the problem of information asymmetry is less severe" (Zajac, 1990, p.220). Ultimately, when the successor is a member of the family, the incumbent's information set tends to converge with that of the candidate such that the incumbent's level of information about the candidate's abilities is near perfect.

This line of argument will not generally apply to external candidates such as employees (MBO) or, even less so, to firm external buyers (MBI) due to the reduced time of assessment, number of observation points, and variation of contexts of such appraisals. Due to this information asymmetry, incumbent owners can choose either internal succession candidates with known abilities or external ones with unknown abilities, whereby the pool of potential external successors is typically larger than the pool of internal candidates. Assuming a similar distribution of actual abilities among the candidates from both pools, there is a high probability that the most capable individual will be external due to the larger external pool size. At the same time, however, it is likely that the external pool contains candidates with abilities that are inferior to those of the internal candidates. Because of the lack of knowledge about which of the external candidates is a 'star' and which one is a 'lemon,' firm owners show an inherent preference for family successors if there is an internal candidate with at least a minimum level of ability. ${ }^{1}$

\subsubsection{Mechanisms to reduce the level of information asymmetry}

Prior research shows that individuals rely primarily on two types of mechanisms, signaling and screening, to lower the level of information asymmetry (Stiglitz, 2000). Signaling is the active disclosure of information by the better-informed party (Connelly et al., 2011). In the context of our study, signaling denotes external succession candidates' attempts to demonstrate their abilities to the incumbent decision makers and to differentiate themselves from other, less capable potential candidates. To be effective, a signal must be "alterable" (Spence, 1973, p.357), “difficult or costly for others to imitate and [...] visible” (Arthurs et al., 2009, p.362).

As Spence (1973) suggests, a variety of potential signals to reveal one's abilities exists. In the context of entrepreneurial succession, human capital attributes that positively affect entrepreneurial success - such as education, experience, knowledge and skills (Reuber and Fischer, 1994; Unger et al., 2009, 2011) - could serve as signals of a candidate's entrepreneurial abilities. Henceforth, we will concentrate on two of these signals, education and prior work experience, which will serve as proxies in our quantitative testing of the hypotheses.

One of the most commonly studied signals to express superior individual abilities is education (Spence, 1973). A capable candidate can obtain a high level of education at a lower cost and with a lower level of effort than a less capable candidate and can easily communicate his or her educational achievements to outsiders. As the potential future benefits (e.g., the transfer of a business) are likely to outweigh the cost of education for - and in most cases only for - a highly capable candidate, education fulfills the formal criteria outlined above for signaling.

Education serves as a valid signal not only in the job market (Spence, 1973) and in the selection of CEO successors for large corporations (Hitt and Tyler, 1991; Zhang and Wiersema, 2009), but also in the entrepreneurial transfer context. Indeed, job markets and entrepreneurial markets exhibit many similarities. In both markets, the decision maker (i.e., the employer or the entrepreneur) takes decisions under uncertainty because of the dearth of information regarding the abilities of the candidate (i.e., the prospective employee or successor). Moreover, in both cases, there is a great deal at stake for the decision maker. Just as the employer fears hiring an unproductive person and consequently having to pay wages for inferior job performance, the entrepreneur is apprehensive about risking the future prosperity of the firm. The level of comparability of the task complexity faced by the entrepreneurial successor and

\footnotetext{
${ }^{1}$ From a statistical standpoint, this assumption requires risk averse behavior by the decision maker. This assumption is reasonable because the incumbent owner in a transfer situation will feel connected to the firm and is therefore likely to be loss averse in contemplating the transfer of the firm to a successor.
} 
the employee largely depends on the specific job requirements, which Spence (1973) did not specify in detail. Two fundamental differences between the two markets exist. First, an employer can reverse erroneous decisions at a later point in time by terminating the work contracts of employees with insufficient abilities, but a former owner does not usually have a way to alter the ownership and management status of the successor after the sale of the firm. Second, in the course of his or her professional life, an employer typically makes a large number of employment decisions, but unless firm owners are habitual entrepreneurs, they usually exit a business only once. A probable consequence of these two differences is that firm owners who are making decisions about a successor, as compared to employers, will be less likely to learn about the actual effectiveness of signals and screening measures. Considering the described similarities and differences, we conclude, that findings on job market signaling (Spence, 1973) can be diligently adapted to the entrepreneurial market.

The notion of education as a valid signal of an entrepreneur's abilities is also captured by authors active in other disciplines. As many scholars have noted, "[e]ducational level reflects an individual's cognitive ability and skills" (Jiang et al., 2012, p.51; referring to Wiersema and Bantel, 1992) as well as his or her capacity to perform important leadership tasks such as processing information, handling administrative complexities and driving change (Westphal and Zajac, 1995). Jiang et al. (2012, p.51) argue that "a higher level of education earned by the entrepreneur may increase stakeholders' confidence in their capability of managing a new business (Carter et al., 2003) and signal potential lenders, employees, and customers about the future productivity of the business (Backes-Gellner and Werner, 2007)."

As an effective signal, high levels of education indicate candidates' superior abilities to the incumbent firm owner, thus dismantle the information asymmetry between the incumbent and the external succession candidate, and ultimately diminish the owner's natural tendency to favor a family internal successor. As a consequence, the probability of an external exit route increases. We therefore argue that the higher the succession candidate's level of education, the more likely is an external as compared to an internal exit route. Put formally,

H1a. The probability of an external as opposed to a family internal exit route increases with the succession candidate's level of education.

A second effective signal in the context of entrepreneurial exits is the prior general work experience of the succession candidate (Unger et al., 2011). Similar to the argumentation applied for education as a signal, professional experience is alterable by the candidate and visible to the outsider, that is the incumbent owner. Moreover, the cost and effort associated with obtaining appropriate work experience are lower for a candidate who has superior abilities than for a candidate who has inferior abilities. As a human capital investment, there is a (modest) positive association between professional experience and entrepreneurial success (Unger et al., 2011), rendering such experience an effective signal in the context of entrepreneurial exit (Aidis and van Praag, 2007; Kim et al., 2006). A long period of professional experience may be associated with the accumulation of task-specific and general knowledge, increased familiarity with challenging professional situations, and previous exposure to a variety of business and entrepreneurial contexts. As a consequence, one can assume that due to various learning effects, individuals with longer professional experience have acquired the capabilities over time that they require to successfully manage a firm (Parker and van Praag, 2012).

In analogy to our theorizing on the effect of candidates' education on the probability of external exits, we argue that longer periods of a candidate's professional experience prior to the incumbent entrepreneur's exit reveal the capable candidate's abilities to the owner, diminish the information asymmetries, and consequently increase the probability of an external exit. Formally,

H1b. The probability of an external as opposed to a family internal exit route increases with the duration of the succession candidate's professional work experience.

In addition to signaling that is accomplished by the individual with the superior information (here, the succession candidate), screening activities conducted by the individual with the inferior information (here, the incumbent) effectively reduce information asymmetry (Garen, 1985; Lee and Venkataraman, 2006; Stiglitz, 1975). Screening comprises all active efforts that the less-informed party initiates to acquire improved knowledge about the transaction partner. In general, greater investments of money and effort in screening yield superior information (Riley, 1979).

In the context of entrepreneurial exits, incumbents can use a broad spectrum of screening techniques that require varying levels of effort to obtain information about the abilities of an external succession candidate. Similar to the arguments on education, job market screening mechanisms such as inspecting job application documents (Lee and Venkataraman, 2006; Riley, 1979) can be adapted to entrepreneurial exits: low-effort screening includes the application of formal selection criteria based, for instance, on previous entrepreneurial experience; more advanced and costly routines, which in turn are likely to render more detailed and reliable information, encompass assessment centers or temporary employment before the transfer.

High investments in screening activities yield superior information about the external candidate's abilities, thus mitigating information asymmetry. In line with our earlier reasoning, we thus hypothesize that this decreased information asymmetry heightens the probability of an external transfer. We also propose, however, that such a monotonically increasing relationship is only valid until a certain level of screening. Although high levels of screening further decrease (albeit marginally) the incumbent's information asymmetry, potential candidates might be deterred by excessive screening for two major reasons: First, excessive screening such as probationary contracts might be costly for highly qualified succession candidates due to their opportunity costs (Riley, 1979). Second, based on the assumption that intrinsically motivated candidates act as stewards rather than as agents, they might feel demotivated by the incumbent's control mechanisms (Chrisman et al., 2007) which "lower stewards' motivation, negatively affecting their pro-organizational behavior" (Corbetta and Salvato, 2004, p.360). Both factors might reduce a potential candidate's interest 
in pursuing the succession process and could ultimately block what might otherwise have been a successful external transfer of control.

In sum, information asymmetry can be reduced via screening activities, which in turn could increase the likelihood of an external transfer. Above a certain level of screening, however, potentially eligible candidates will lose interest in becoming successors; thus, the probability of an external exit route will decrease with rising screening activities above the threshold level.

H2. The probability of an external as opposed to a family internal exit route is related to the incumbent's screening effort in an inverted U-shaped form.

\subsection{Non-economic rationales: firm age as driver of emotional attachment}

Our reasoning up until this point has been based on the role of asymmetric information in entrepreneurial exit choices and has emphasized the economic factors that influence such decision making. However, owners' preferences regarding these decisions are also likely to be influenced by non-economic factors such as legacy concerns. In particular, firm age, which serves as proxy for the duration of its ownership by the incumbent owner and his/her family (Zellweger et al., 2012), is associated with heightened emotional attachment to the firm (DeTienne, 2010). It subsequently increases the reluctance to pass the business to a family outsider (Salvato et al., 2010; Sharma and Manikutty, 2005) because over a long period of ownership, the identity of incumbent owners often becomes inextricably intertwined with that of their firms (Berrone et al., 2010; Cruz et al., 2010a). This is in line with recent research on the concept of socioemotional wealth (SEW) among firm owners (Chrisman and Patel, 2012; Gómez-Mejía et al., 2007), which encompasses all socioemotional elements of the owner's utility functions that relate to the "stock of affect-related value" (Berrone et al., 2010, p.82) invested in the firm. Research on SEW and behavioral theory reveals that, over time, owners build up non-economic utility and attachment to the firm, which, in turn, influences entrepreneurial behavior substantially (Cyert and March, 1963; Wiseman and Gómez-Mejía, 1998; Zellweger et al., 2012).

Zellweger et al. (2012) argue that SEW perceptions grow over time as a result of extended self-attribution (Belk, 1988; Boyce et al., 1992). Over time, possession rituals imbue the owned asset with a personal meaning that establishes a connection between owner and asset, resulting in a perceived singularity in the owner-asset-relationship (Grayson and Shulman, 2000). If ownership has been passed on within the family during a long period of time, the asset will possess a high level of historicity. In such cases, the ownership stake in the firm becomes part of the owner's legacy and comes to be seen as a sort of heirloom. As a consequence of those increased stocks of SEW, with mounting experience owners exhibit increasing preference for the status quo (Burmeister and Schade, 2007), which is the internal succession mode in our setting.

We therefore argue that incumbents of old firm are less willing to "let their business go" to external successors because doing so would decrease SEW, whereas family internal exit routes would preserve SEW. We accordingly propose that firm age, which entails emotional attachment, decreases the probability of an external vs. internal transfer of control.

H3. Firm age, as a driver of emotional attachment, is negatively related to the probability of an external as opposed to a family internal exit route.

\subsection{Interactive effects of economic and non-economic rationales}

Up to now, we have studied the effects of economic and non-economic determinants of exit route decisions separately. In the following, we will investigate how economic and non-economic factors in combination affect the choice of exit routes. In particular, we will investigate how firm age moderates the hypothesized main effects of education, work experience, and screening.

As outlined in Section 3.1.2, signaling and screening activities often reveal superior abilities of external as compared to family internal candidates. Assuming purely rational decision making, one would expect incumbent owners to opt for an external exit in such cases.

However, building on prospect theory (Kahneman and Tversky, 1979), we argue that biases exist that cause incumbent entrepreneurs to deviate from purely rational decision making and that this effect is stronger the older the firm is. Over time, as argued in Section 3.2, owning families build up stocks of socioemotional wealth (Gómez-Mejía et al., 2007; Zellweger et al., 2012) and the respective incumbent entrepreneurs become more and more emotionally attached to their firms. Those ties entail endowment effects (Knetsch, 1989) and a preference for the status quo ('status quo bias'), which is, in the context of our study, the continuance of the family influence and hence the transfer of the business to a family internal successor. In other words, owners will desire to pursue an exit route option that allows them to preserve their socioemotional wealth.

Such status quo biases have to two important consequences for the entrepreneurs' decision making. First, because of selective cognitive attention, which results from the increased emotional attachment (Koenig et al., forthcoming), incumbent owners of old firms are less likely to recognize relevant signals sent by capable external succession candidates. As a consequence, the effectiveness of external candidates' signaling activities weakens with firm age.

Second, even if incumbent entrepreneurs of old firms are aware of the information carried by signaling and screening activities, their status quo bias induces them to 'downplay' any information that contradicts their inherent preferences for internal succession and endangers the future socioemotional wealth (Gómez-Mejía et al., 2007; Koenig et al., forthcoming). For instance, incumbents will - consciously or unconsciously - discount any (positive) information on external candidates' abilities, obtained from either signaling or screening activities, and will hence be prone to under-estimate the abilities of external succession candidates (Lord et al., 
1979). Put differently, even if incumbent owners decide to actively engage in screening activities, there is a high probability that confirmatory bias, which increases with firm age, restrains them from objectively evaluating the information gained and hence reduces the effectiveness of mechanisms that reduce information asymmetries.

Taken together, firm age, mediated by status quo bias, moderates the effects of signaling - that is education and work experience - and screening on the probability of external exits.

H4a. The positive effect of education on the probability of an external as opposed to a family internal exit route is attenuated by firm age as driver of emotional attachment.

H4b. The positive effect of work experience on the probability of an external as opposed to a family internal exit route is attenuated by firm age as driver of emotional attachment.

H4c. The inverted U-shaped effect of screening on the probability of an external as opposed to a family internal exit route is attenuated by firm age as a driver of emotional attachment.

\section{Methods}

\subsection{Sample}

We test our hypotheses using a sample of small- and medium-sized (less than 250 employees), privately held firms from Germany, Switzerland, and Austria that had been transferred to one or several individuals within the previous 10 years. We restricted our sample to small- and medium-sized firms because transfers to one or several individuals (which constitute the focus of our investigation) occur more frequently with such businesses than with large enterprises.

To create our sample, we obtained the addresses of 42,500 randomly chosen small- and medium-sized firms from the Dun \& Bradstreet databases of the countries in question. One third of these businesses were medium (50-249 employees), one third small (10 to 49 employees) and one third micro enterprises ( 0 to 9 employees).

We mailed a comprehensive questionnaire to the current owner-managers of the sampled firms. The response rate was $10.3 \%$, which is comparable to the response rates of other studies that targeted entrepreneurs and top-managers (Cruz et al., 2010b; Eddleston et al., 2012; Schulze et al., 2001). We restricted our final analysis to the responses of owner-managers who had taken over their businesses within the previous 10 years (1036 survey responses). 423 of those returned questionnaires contained missing data and were thus excluded from the analysis, resulting in a final sample size of 613 observations. As a post-hoc test for biases caused by the missing data, we employed multiple imputation techniques ${ }^{2}$ (Rubin, 1987). The results of our analysis with three imputations used to simulate plausible values for our missing controls, which showed a non-nested missingness pattern, (Schafer, 1999) were not substantially different from the original results we obtained (which are reported in Section 4.3; all of the hypothesized effects except the firm age/screening interaction were supported). This finding suggests that systematic bias, a core threat of missing values (Schafer and Graham, 2002), is unlikely to be a concern in our study. ${ }^{3}$

Following other studies of privately held firms (e.g., Kellermanns et al., 2008), we employed a key informant approach (Kumar et al., 1993; Seidler, 1974) assuming that CEOs are the individuals who are most substantially and directly involved in the entrepreneurial exit processes. To assess the risk of non-response bias, we compared the data obtained from early and late respondents using a one-way ANOVA for which the order in which the responses were returned was used as the determining factor. This test is based on the assumption that late respondents are more similar to non-respondents than to early respondents (cf., Chrisman et al., 2004; Oppenheim, 1966). We found no statistically significant differences between early and late responses in terms of our explanatory variables mitigating concerns about non-response bias. To assess the degree to which our sample is representative of the total population of SMEs that have recently undergone succession in the countries in question, we compared the descriptive characteristics of our sample with the characteristics of the samples used in comparable studies. The average age of the firms in our sample (62 years) is comparable to the average age of the firms in a sample containing German and Swiss family businesses investigated by Zellweger et al. (2012) (67 years for Swiss firms and 49 years for German firms), and it is older than the average age of the firms in a sample of startup firms included in the 2007 Global Entrepreneurship Monitor's (GEM) report on Swiss firms (17 years) (Volery et al., 2007) and German firms (19 years) (Sternberg and Lückgen, 2005). The average age of the owner-managers of the firms in our sample ( 45 years) is similar to the average ages of the owner-managers of the Swiss firms (46 years) and the German firms ( 44 years) in the GEM reports, and it is younger than the average age of the owner-managers of the firms studied by Zellweger et al. (2012) (51 years for Swiss firms and 52 years for German firms). This difference is reasonable because our focus is on owner-managers who only recently succeeded the incumbent owners, whereas the sample studied by Zellweger et al. includes successors as well as incumbent owners. GEM, on the other hand, focuses on founders, i.e., individuals who recently started businesses.

\footnotetext{
2 Based on STATA's multiple imputation command set (mi).

3 We thank one anonymous reviewer for pointing us to this additional robustness test.
} 
Next, we assessed the likelihood of common method variance, which is caused either by drawing on the same source to obtain the dependent and the independent variables or by specific item characteristics that strengthen respondents' tendency to answer the survey questions in a distorted way. We took several ex ante procedural steps during the data collection process to decrease the risk of this type of error. First, the items were fact-based and constructed in the simplest manner possible (Tourangeau et al., 2000). As common method bias is mostly related to perceptual measures, the fact-based variables used in our questionnaire are unlikely to be affected by such problems (Chang et al., 2010). Second, the questionnaire that we used was embedded in a comprehensive survey on the economic relevance of entrepreneurial exits within the German-speaking areas of Europe. This overall design and the particular order of the questions within the questionnaire did not provide the respondents any indication of the expected correlations. It is therefore unlikely that the respondents "edit[ed] their responses to be more [...] consistent with how they [thought] the researcher want[ed] them to respond" (Podsakoff et al., 2003, p.888). Third, we assured the respondents of the strict confidentiality of their anonymous responses, thereby decreasing the probability of social desirability bias in respondents' answers (Podsakoff et al., 2003). For an ex-post verification that our procedural efforts to reduce common method variance were effective, we performed a single-factor test, as suggested by Podsakoff and Organ (1986). An exploratory factor analysis of all of the variables used in this study revealed two factors with Eigenvalues greater than one, jointly accounting for $50.1 \%$ of the total variance. To further eliminate concerns regarding common method bias, we conducted a confirmatory factor analysis (Podsakoff et al., 2003). The corresponding structure fits the data $(\mathrm{CFI}=0.2685, \mathrm{RMSEA}=0.1128)$ better than the one-factor structure $(\mathrm{CFI}=0.0000, \mathrm{RMSEA}=0.1286)$. In $\mathrm{sum}$, the various ex-ante precautions and the results of the post-hoc analyses indicate that common method variance is unlikely to distort the results of our study (Podsakoff et al., 2003).

\subsection{Variables}

\subsubsection{Dependent variable}

We measured the dependent binary variable, choice of exit route, by asking survey respondents whether the last entrepreneurial exit (i.e., the most recent transfer of ownership and management of their firm) was family internal (0) or external (1). Family internal exit routes were defined as handing over the firm to a child, another relative by blood or law (spouse, nephew, etc.), or several relatives as group. External exits include transfers to individuals or groups of individuals to whom the incumbent has no familial ties; thus, in line with Wennberg et al. (2011), encompassing MBOs and MBIs, but excluding transfers to institutional buyers. Our sample does not include any ambiguous cases in which two or more individuals who were internal and external to the family jointly assumed control.

\subsubsection{Independent variables}

We assessed the level of education by ranking survey respondents' indications of their highest educational achievement on a 7-point scale: no completed education (0), elementary and secondary school (1), high school diploma (2), apprenticeship (3), master craftsman (4), university degree (5), and doctoral degree (6). Moreover, we asked the respondents to indicate in years the length of their general work experience prior to the succession. To determine the level of screening, we asked the survey respondents to indicate screening efforts made by the incumbent before the transfer of the firm to the successor on a 7-point scale: review of certificates (0), review of recommendation letters (1), the use of head-hunters (2), trial work (short-term) (3), the use of assessment centers (4), management participation (short-term) (5), and management participation (long-term) (6). To test the hypothesized curvilinear relationship for screening activity, we also calculated the squared value of the term for screening.

\subsubsection{Moderating variable}

To obtain information regarding firm age (in years), we asked the respondents about the year the firm was founded. We calculated the interaction term for firm age and education, work experience, screening as well as screening squared.

\subsubsection{Control variables}

We controlled for firm size using the natural logarithm of the number of employees. Two types of influence are conceivable: First, small firms might find external exits more difficult because it is challenging to attract the interest of qualified external candidates. Alternatively, it might be more difficult for larger firms to employ external exits because of the increased investment that would be involved and the consequential financing obstacles that the successor might encounter.

Moreover, we controlled for the number of shareholders at the time of the firm transfer, since more shareholders might hamper consensus regarding a family internal candidate. Similarly, we controlled for the number of managing directors at the time of the transfer because a larger number of managing directors could potentially increase the number of candidates interested in a buyout. Next, we included a time dummy variable indicating whether the succession took place more than 5 years earlier (with a value of 1 for distant exits). The purpose of this control was to rule out any time-effects and/or to check for unobserved environmental effects that might have affected exit decisions that occurred more than 5 years before the date the respondent completed the survey. To control for any cultural or legal differences that might have affected the choice of external vs. internal exit routes, we included country-level dummies (Germany, Switzerland, and Austria). We also controlled for industry as a proxy for risk and the economic outlook of the firm because such factors could potentially influence particularly the interest of external buyers.

Last, we included a dummy variable for the financing structure used in the transfer process to account for whether an earn-out structure was applied. When the incumbent maintains an ownership stake post-succession, he or she experiences ongoing risk exposure and is likely to continue participating in business-related decisions. Earn-outs, which are intended to reduce information 
asymmetry regarding the behavior post-succession, are potentially related to external exit routes. We coded transfers structured as earn-outs as 1 and others as 0 .

\subsection{Controlling for endogeneity}

As the availability of willing and capable family members is necessary for successful family internal exits (De Massis et al., 2008; Sharma et al., 2003), we had to account for the possibility that some incumbent owners may have been forced to choose an external exit route in the absence of family members as succession candidates. Even though we lack detailed data about the family structure of the incumbents, we believe that such potential self-selection bias does not undermine our reasoning and findings for two reasons. First, we employed a broad definition of family internal exits, including not only transfers to direct descendants of the incumbent, but also transfers to more distant relatives, including in-laws. Therefore, it is unlikely that the incumbent owners would not have had any potential family candidates to consider and would thus have been forced into the external category. Second, to further allay endogeneity concerns, we employed the two-step approach developed by Heckman (1979). We first estimated a binary dependent variable model to identify the probability of selection into either of the two exit groups. As a selection variable, we used a binary variable indicating whether ownership and management were transferred simultaneously or at separate points in time. We argue that simultaneous transfer is more likely in cases involving an external successor and sequential transfer in cases involving an internal successor (Sharma and Manikutty, 2005). Based on this estimation, we calculated the inverse Mills ratio, which we include in our logit estimation to control for self-selection bias.

\subsection{Analyses and results}

\subsubsection{Descriptive data}

Table A.1 presents a correlation matrix and descriptive statistics for all of the variables used in the models reported. In general, the correlations only reach low to moderate levels. To reduce issues caused by nonessential multicollinearity in the squared and interaction terms, which could entail inflated standard errors and hence insignificance in hypotheses testing (Aguinis, 1995; Hair et al., 2006), we centered all of the variables by subtracting their respective means (Aiken and West, 1991; Dalal and Zickar, 2012; Li and Tang, 2010). Furthermore, we examined the variance inflation factors of our estimation variables; the variance inflation factors ranged from 1.06 to 2.87, with an average of 1.41, and were thus below the generally established threshold of 10 (Hair et al., 2006; Tabachnick and Fidell, 1996).

As Table A.1 shows, slightly more than $75 \%$ of the businesses were transferred to owner-managers with familial ties to the incumbent owner, whereas the remaining $25 \%$ were transferred to external successors. The average level of education was 4.02 (standard deviation 1.23), the average level of prior work experience was 12.69 years (standard deviation 8.78), and the average level of screening was 3.80 (standard deviation 2.76). In terms of these values, there were no substantial differences between old and young firms.

To account for any differences between $\mathrm{MBO}$ and $\mathrm{MBI}$, we ran a multinomial logit estimation for the three outcomes categories: "internal", "external (MBO)", and "external (MBI)" prior to our analysis of family internal vs. external (MBO and MBI) exit routes, treating MBO as the baseline category. The results obtained from the multinomial logit estimation reveal significant differences between the MBO and MBI options regarding only two predictor variables. First, the effect of education is positive and significant $(\beta=$ $0.566 ; \mathrm{p}<.05$ ) for MBI as compared to MBO. This result is consistent with our theory because it indicates that education is particularly important as a signal in situations in which information asymmetry is severe (owners have less information about the abilities of MBI candidates than those of MBO candidates). Second, the effect of the interaction between education and firm age is positive and significant for MBI as compared to $\mathrm{MBO}(\beta=0.015 ; \mathrm{p}<.05)$. Because the theoretical arguments that are presented above suggest that there should be no difference between MBI and MBO in relation to this variable, we will discuss the implications of this result in the Discussion section.

\subsubsection{Results of logit regression}

To analyze the direct and moderated effects of the independent variables on the binary dependent outcome, we employed logit regression (see Table A.2). In Models 1 through 3, the occurrence of an external exit (1) as opposed to an internal exit (0) constitutes the dependent variable. Model 1 includes only the control variables; the independent variables and the interactions terms of the moderator were added subsequently in Models 2 to 3.

The coefficients of Models 1 to 3 indicate the influence of the variables on the logarithmic odds ratios of external vs. internal exit routes (Folta and O'Brien, 2004; Hoetker, 2007; Li and Tang, 2010). Model 1 shows that the logarithmic odds that a firm will be externally transferred are negatively and significantly related to the size of the firm $(\beta=-0.232 ; p<.05)$. In contrast, the number of shareholders exerts a positive and significant effect on the logarithmic odds of firms being sold to external parties $(\beta=.113 ; p<.05)$, whereas temporal distance exerts a negative and significant effect on these odds $(\beta=-.503 ; p<.05)$. Furthermore, there are national and industry-related differences in these odds (with Switzerland having $\beta=1.459 ; \mathrm{p}<.001$ and primary sector having $\beta=-0.968$; $\mathrm{p}<.01$ ). Overall, Model 1, which contains only the control variables, yielded a $\chi^{2}$ value of 102.501 . In Model 2, we added education, professional experience, screening, and firm age to the equation as independent variables. Education level affected the logarithmic odds of external exit routes positively and significantly $(\beta=.296 ; \mathrm{p}<.01)$. Furthermore, professional experience had a positive and highly significant influence $(\beta=0.080 ; p<.001)$. The linear term of screening had a positive and significant effect $(\beta=0.545 ; p<.05)$, whereas the squared term of screening had a negative and significant influence $(\beta=-.140 ; p<.01)$. Firm age had a negative and 


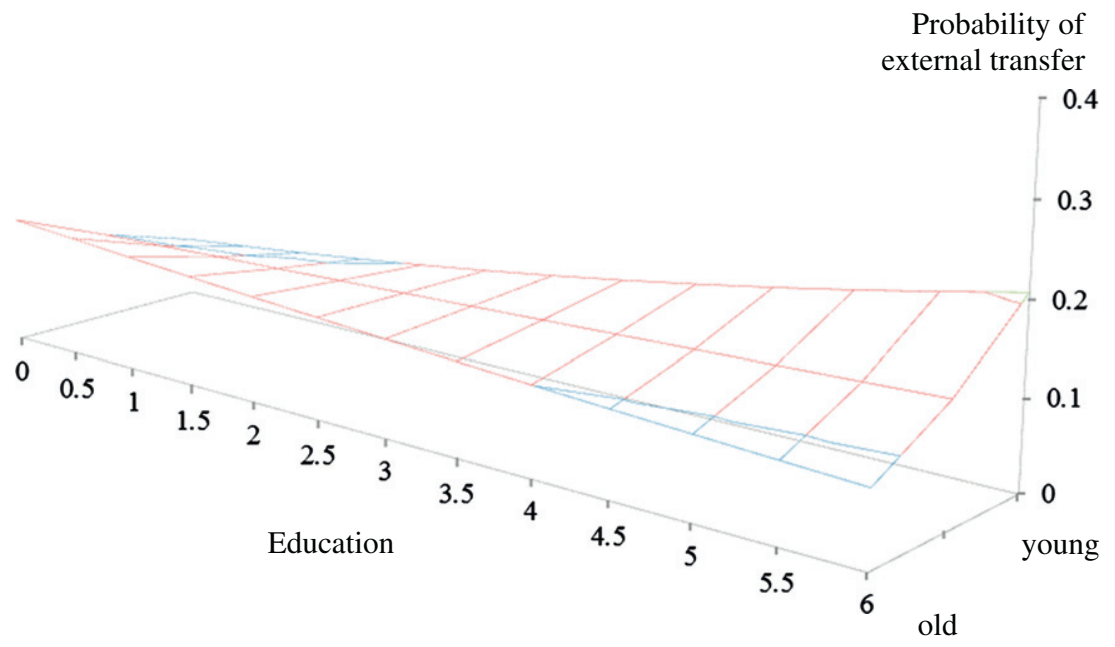

Fig. 1. Effect of education and emotional attachment on the probability of external exit routes.

highly significant influence $(\beta=-.017 ; \mathrm{p}<.001)$. Thus, H1a, H1b, H2, and H3 were all fully supported. The model fit is higher compared to Model 1 at a $\chi^{2}$ value of 180.380 .

Finally, Model 3 includes the interaction effects. We found that the interaction between education and firm age had a negative and significant effect $(\beta=-0.008 ; \mathrm{p}<.05)$ consistent with $\mathrm{H} 4 \mathrm{a}$. We found no significant effect for the interaction between professional experience and firm age, which lead us to reject $\mathrm{H} 4 \mathrm{~b}$. We also found that firm age moderated the screening and screening squared variables $(\beta=.012 ; \mathrm{p}<.05 ; \beta=-0.003 ; \mathrm{p}<.05)$, which confirmed H4c. ${ }^{4}$ The $\chi^{2}$ value for Model 3 (189.035) is the highest and the model's Akaike information criterion (528.340) is the lowest, suggesting that Model 3 is the best fitting model (Hoetker, 2007).

\subsubsection{Interpretation of results}

As logit estimation is a non-linear model, its coefficients cannot be directly interpreted as the marginal effects of an independent variable on the dependent variable because each marginal effect also depends on the level of all of the others (Hoetker, 2007; Wiersema and Bowen, 2009). In order to account for differences in data interpretation between OLS and logit estimation, we provide a graphic illustration as supplementary analysis (Zelner, 2009), which is particularly relevant in analyses with interaction terms (Wiersema and Bowen, 2009); it "provide[s] a richer understanding of variables' effects" (Hoetker, 2007, p.335) as the central focus of the analysis is the effect of the variables on the predicted probabilities rather than the logarithmic odds.

Following Hoetker (2007), we predicted the probability of the external exit route according to Model 3 by varying educational levels (Fig. 1), duration of work experience (Fig. 2) and screening activities (Fig. 3) for different levels of firm age. We set the sector dummy at 1 for the secondary sector (all other sector dummies were set at 0 ), the nationality dummy at 1 for Germany (the Switzerland dummy was set at 0), and the values for all of the other variables at their means (see also Mishina et al., 2010) thus following best practice (Long and Freese, 2005). To calculate the predicted probabilities, we used the STATA-Spost package. ${ }^{5}$ Figs. 1,2 , and 3 show the relationships between each of the independent variables, the moderator and the probability of an external transfer.

Fig. 1 shows that for young firms the probability of an external transfer rises from $7.0 \%$ to $20.8 \%$ as the education level of the successor increases. This effect of education weakens when firms age, however. The probability of an external successor with a high education decreases from $20.8 \%$ for young to $8.2 \%$ for old firms. These findings are in line with H1a and H4a.

Fig. 2 shows the effects of work experience and firm age on the probability of external exit routes. Similar to education but to a greater degree, work experience increases the probability of an external transfer from $1.2 \%$ ( 0 years of experience) to more than 90\% (24 years of experience) for young firms. On the other hand, the effect of work experience is largely absent for old firms (probability of external exit route below 1\%). These findings support $\mathrm{H} 1 \mathrm{~b}$ as well as the previously rejected H4b. Interestingly, the graphical illustrations in Figs. 1 and 2 show that for old firms, the probability of an external successor with a low ability level (in terms of education/work experience) is slightly higher than it is for a young firm. This case, which is not covered by our hypotheses, is interpreted in the Discussion section.

\footnotetext{
${ }^{4}$ In an additional analysis, we ran regressions separately for each of the proposed interactions. The results of those separate regressions are robust compared to those of Model 3 and thus support the estimation results from our analysis.

5 http://www.indiana.edu/ jslsoc/spost.htm.
} 


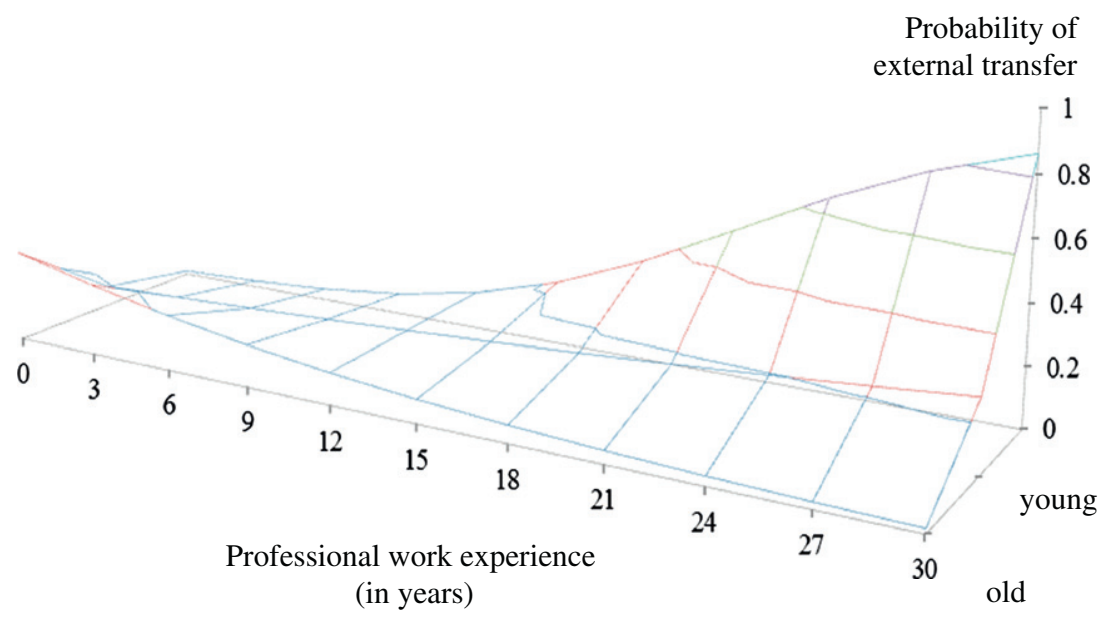

Fig. 2. Effect of professional experience and emotional attachment on the probability of external exit routes.

Fig. 3 displays the effect of the incumbents' screening activities and firm age on the probability of an external transfer. For young firms, we find evidence of an inverted U-shaped relationship, as predicted in H2, with the probability rising from $15.9 \%$ (when there is no screening) to $37.0 \%$ (at a medium level of screening) and then declining again to $11.5 \%$ (under extensive screening). For older firms, the effect of high screening levels is weaker, as predicted in $\mathrm{H} 4 \mathrm{c}$, resulting in a probability of external transfers of less than $5 \%$. Moreover, the probability that an external will be selected as the successor when there is no screening decreases further, yet, contrary to our hypothesis, the effect under medium levels of screening is not weakened.

\section{Discussion}

The objective of our study was to investigate the role of information asymmetry as an antecedent for external versus internal entrepreneurial exit routes in privately owned SMEs of various ages. We hypothesized and empirically demonstrated that owners, ceteris paribus, prefer family succession. In fact, we found that the overall probability of external transfers in our sample was less than $25 \%$ (see Table A.1). When no measures were used to reduce information asymmetry this ratio declined even more (to less than $16 \%$ ), as illustrated in Figs. 1, 2 and 3. As such our findings are in line with those of other theoretical and empirical studies in the family business literature that address the tendency of incumbent owners to choose internal transfer (e.g., De Massis et al., 2008; Le Breton-Miller et al., 2004; Lee et al., 2003). However, our findings extend the literature by addressing not only transfers of management (e.g., Bocatto et al., 2010; Le Breton-Miller et al., 2004; Lee et al., 2003; Sharma et al., 2003), but also the simultaneous transfer of ownership and management. This broader scope has been recognized as important yet sparsely studied (Birley and Westhead, 1993; Le Breton-Miller et al., 2004). Our study also makes a theoretical contribution by using information asymmetry to

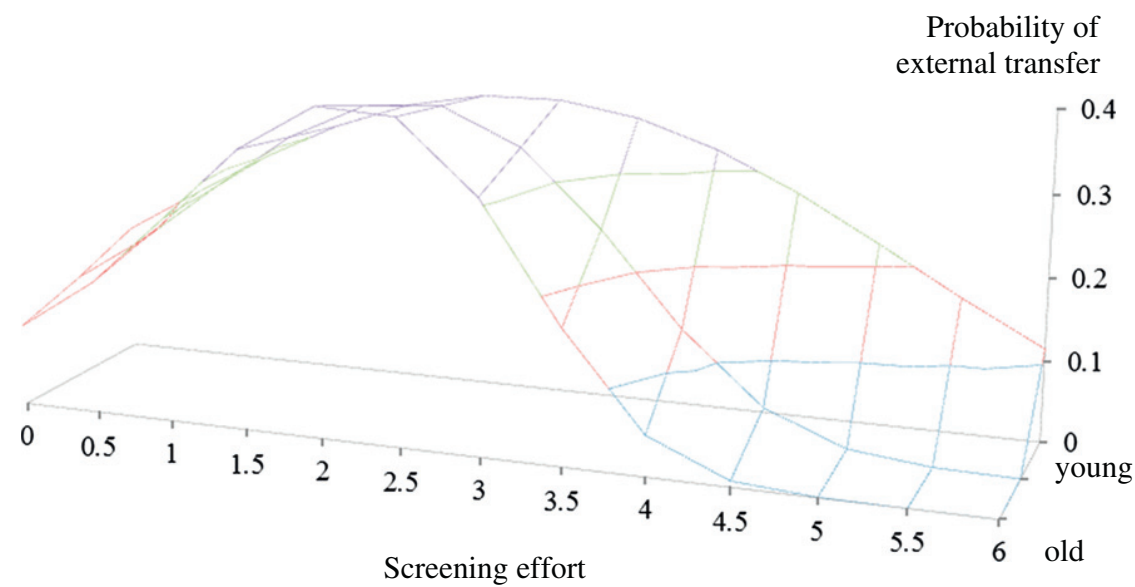

Fig. 3. Effect of screening and emotional attachment on the probability of external exit routes. 
explain the tendency of firm owners to prefer internal transfers. Therefore, our study has heeded the call for more nuanced research on succession (Sharma et al., 2012) and invoked the emerging stream of literature that explains succession as a function of economic factors (Lee et al., 2003; Royer et al., 2008).

Moreover, our descriptive data show that incumbent entrepreneurs are highly inclined to screen succession candidates (average of 3.8 on a scale from 0 to 6), although screening techniques are by nature costly and time-consuming. As such, our quantitative data provide support for the qualitative findings of Graebner and Eisenhardt (2004), and the conceptual arguments presented by DeTienne (2010) who insisted that an owner's caring for his or her firm will often not end when the business is sold; yet the owner is concerned about the future prosperity of the business and thus searches for a capable candidate to continue business operations. Most family business studies address emotional attachment and SEW among members of business families only for the duration of family ownership, yet, our quantitative data indicate that concerns regarding the prosperity of the firm may continue beyond this period.

The results of our logit model, combined with the graphical interpretation of the results support our initial hypotheses (H1a, $\mathrm{H} 1 \mathrm{~b}$, and $\mathrm{H} 2$ ) that several mechanisms that alleviate information asymmetries - education and work experience of the succession candidate as signal of his or her superior abilities as well as the incumbents' screening efforts - affect the probability of an external transfer of ownership and management. As such, our study follows the call for more quantitative, empirical research on entrepreneurial exits (Morris and Williams, 1997) and contributes to the emerging stream of literature that examines the antecedents of exit route decisions (Cardon et al., 2005; DeTienne, 2010; DeTienne and Cardon, 2012; Wennberg et al., 2010), which, ultimately, influence firm performance and survival. Our study extends beyond previous work, however, by not exclusively considering the owner's perspective (e.g., DeTienne and Cardon, 2012; Graebner and Eisenhardt, 2004); rather, we ensure a more comprehensive account of this dyadic setting by considering how incumbent owners and succession candidates attempt to eliminate information asymmetry. By doing so, we demonstrate that asymmetrical information is a critical determinant that influences incumbents' exit route choices. This finding constitutes an important contribution to literature, because so far information asymmetry, despite its relevance, has only recently been employed in the context of entrepreneurial exits (Howorth et al., 2004; Scholes et al., 2007; Scholes et al., 2008) and has thus far been applied solely to the successor (e.g., Dawson, 2011; Wennberg et al., 2011).

In addition to our empirical findings regarding the effect of economic factors, our results regarding firm age (H3, H4a, and H4c) show how non-economic factors are likely to influence exit route choices. To the best of our knowledge, this is the first study to integrate information asymmetry and research on SEW and to provide empirical evidence of the combined effect of economic and non-economic antecedents of exit route decisions. Moreover, our study contributes to the growing body of research on SEW (e.g., Berrone et al., 2012; Chrisman and Patel, 2012; Gómez-Mejía et al., 2007, 2011; Zellweger et al., 2012) by shifting the unit of analysis from the widely studied family level to the sparsely studied individual level. While our logit results mostly confirm the prediction that increasing firm age directly decreases the probability of an external transfer and weakens the relationship between signaling or screening and the probability of an external transfer, the results of our graphical analysis provide first evidence that these mechanisms might be more complex than initially assumed. For example, the 3D graph of the interaction between screening and firm age (Fig. 3) shows that firm age weakens the probability of external transfers in cases of either low or high screening efforts but has no influence under medium-level screening efforts. One possible explanation for this effect lies in a potentially ambiguous impact of firm age, assuming that for some owners of old firms the desire to find the most capable successor granting future firms prosperity might transcend his or her preference for internal successors. As a consequence, such owners might be inclined to use medium-effort screening techniques to identify the most capable (external) successor. Moreover, the unexpected increase in the probability of an external transfer among old firms when the level of the candidates' education or work experience is low requires further investigation. While there is no information regarding the significance of these specific data points, the findings could be preliminary indicators of further 'irrational' decision making in old firms when the owner's level of emotional attachment is high. Another indication that emotional attachment may play a more complex role is the difference between MBO and MBI exit routes (see also Section 4.4.1), showing a significant positive effect of the interaction of education and firm age on the probability of an external transfer for MBI versus MBO: If - for any reason - an incumbent owner 'self-selected' him- or herself into the group of external exits, increased emotional attachment might lead to increased concern about the future prosperity of the firm and hence increase the owner's sensitivity for and acceptance of firm-external (educational) signals.

Lastly, our findings are also important for research on information asymmetry (e.g., Spence, 1973, 1976; Stiglitz, 1975, 1977, 2000) as we theorized on and found empirical support for a 'flip side of the coin' regarding the effects of screening. Our results show that alleviating information asymmetry does not have a monotonous effect on the outcome variable because screening initiatives above a certain level may have a reverse effect on the probability of an external transfer, as shown by the inverse U-shaped curve. We argue that this effect stems from the succession candidate's discouragement and the opportunity cost caused by such extensive screening efforts. Additionally, our findings regarding the interaction of screening and signaling with firm age demonstrate how non-economic considerations may affect or offset purely economic decision criteria. Our study thus heeds Connelly et al.'s (2011) call to investigate effects that moderate the influence of signals.

\subsection{Practical implications}

The practical implications of our work are fourfold. First, our results generally reveal the complex decision-making process in the context of entrepreneurial exits in privately held firms. Thus, from the perspective of the involved individuals, paying attention to the incumbent's characteristics, needs, and emotions may be beneficial (e.g., Graebner, 2009; Graebner and Eisenhardt, 2004). 
Second, more specifically, external succession candidates will profit from their educational achievements and prior work experience when they attempt to purchase privately held firms. This is because incumbent owners do indeed care about the capabilities of the person to whom they transfer their businesses and because prior achievements are effective indicators that may lower an owner's concerns about an external successor's abilities. Education is particularly effective for firm external candidates. Third, it is important for incumbent owners to note that moderate screening efforts increase the probability of external successors, whereas excessive screening levels decrease it. Fourth, our results may be taken as an additional indication that the market for the transfer of ownership and management within SMEs is affected by asymmetric distribution of information. As Akerlof (1970) demonstrated with regard to car sales, asymmetric information causes each party to assume a worst-case scenario and ultimately leads to a market breakdown ('adverse selection'). It is crucial for policy makers to acknowledge the information asymmetry inherent to the succession market for SMEs so they will be aware of the potentially detrimental effects of adverse selection and adjust their activities accordingly.

\subsection{Limitations and avenues for future research}

Like any other empirical work, our study has limitations that open up avenues for further research. First and foremost, we draw on data provided by the successor who reflected back on the circumstances of the succession thus rendering additional information about the incumbent such as his or her age, education, and industry experience (DeTienne and Cardon, 2012), as well as the firm's characteristics at the time of transfer unavailable. Such limitations are inherent in most exit route studies and need to be weighed against the size of our sample, which allowed succinct empirical testing. We also believe that retrospective bias is unlikely in our study because our key variables are objective, fact-based, and known to the incumbent (Podsakoff et al., 2003).

Second, we include firms' industry sector to control for risk and concerns about the economic outlook of the firm, but we did not control for firm performance at the time of the transfer. Previous research, however, has shown that firm performance is not a clear predictor of entrepreneurial exit routes (Graebner and Eisenhardt, 2004; Wennberg et al., 2010). Nevertheless, it might be desirable for future research to consider these possible effects. It would also be advisable for researchers to control for the sale price associated with each transaction so as to generate further inferences about incumbent owners' motivation to choose particular candidates.

Third, our use of firm age to show the influence of non-economic determinants of entrepreneurial exit routes is not without limitation as firm age does not necessarily equal the duration of ownership by one family. As a consequence, higher firm ages might not always result in increased emotional attachment and the effect of non-economic determinants might thus be overrated in our study. While firm age provides interesting first quantitative insights into the effect of non-economic determinants of exit route choices, scholars are encouraged to extend this view and combine the effects of information asymmetry with the various emotional barriers identified by previous literature (e.g., De Massis et al., 2008).

Fourth, our study focuses on the effects of asymmetrical information but omits other aspects of the owner-entrant relationship such as the impact of asymmetrical trust (Graebner, 2009). Trust asymmetry might influence the outcome of our analysis, as the level of such asymmetry between the incumbent and potential successors may be lower for internal candidates. Moreover, the use of education and prior work experience which are human capital investments without task relation (Unger et al., 2011) is not without limitation. Replication studies that consider task-specific, knowledge- and skill-related variables could improve the robustness of our findings and rule out alternative explanations (e.g., that education yields better negotiation skills).

Fifth, a more comprehensive consideration of the incumbent's familial circumstances, such as marriage, number of children willing to succeed with at least a minimum of abilities, and eventually also cultural and religious beliefs (Justo and DeTienne, 2008), may open up interesting opportunities of further research, not only on actual exit routes, but also on respective intentions. For example, scholars might investigate which family configurations motivate firm owners to heavily screen both external and internal candidates (Schulze et al., 2001). This is particularly important, as the outcome of reviewing the internal candidates' abilities might affect the entrepreneur's willingness to screen outside candidates as well as his or her attention to signals sent by external candidates and, in turn, bias him or her in the decision to opt for an external exit route. Our study, restrained by data limitations inherent to most empirical studies, only explores a small portion of the much more complex picture of exit route decisions. We thus strongly encourage scholars to more comprehensively take the sequential process of entrepreneurial exit route decisions into account, to test for potential pre-judgments, which could weaken the strength of the identified effects, and consequently rule out any potential concerns about reverse causality.

Finally, our study only investigates successful transfers of ownership and management. Due to the nature of the data collection process, we were unable to comprise failed successions.

\section{Conclusion}

Explaining the variance in the exit paths chosen by entrepreneurs is crucial for predicting those firms' future. Economic factors provide a promising explanation for the tendency of incumbents to transfer their businesses within the family. We show that variance in information asymmetry, caused by variation in the extent to which measures used to alleviate information asymmetry are applied, results in variation in the probability that an incumbent will choose a particular exit path. Moreover, economic-rational factors interact with emotional attachment to the firm, which sheds a new and intriguing light on entrepreneurial exits. 


\section{Appendix}

Table A.1

Means, standard deviations and Pearson correlations.

\begin{tabular}{|c|c|c|c|c|c|c|c|c|c|c|c|c|c|c|c|c|}
\hline & & Mean & S.D. & 1 & 2 & 3 & 4 & 5 & 6 & 7 & 8 & 9 & 10 & 11 & 12 & 13 \\
\hline 1 & External & 0.24 & 0.43 & & & & & & & & & & & & & \\
\hline 2 & Log employees & 3.07 & 1.43 & $-0.1311^{*}$ & & & & & & & & & & & & \\
\hline 3 & Number of shareholders & 2.41 & 2.63 & $0.1150^{*}$ & $0.2346^{*}$ & & & & & & & & & & & \\
\hline 4 & Number of MDs & 1.95 & 1.24 & 0.0177 & $0.3448^{*}$ & $0.2311^{*}$ & & & & & & & & & & \\
\hline 5 & Distant takeover & 0.64 & 0.48 & $-0.1144^{*}$ & $0.0999^{*}$ & -0.0048 & 0.0084 & & & & & & & & & \\
\hline 6 & Germany & 0.54 & 0.50 & $-0.2498^{*}$ & $0.3587^{*}$ & -0.0084 & -0.0734 & $0.1285^{*}$ & & & & & & & & \\
\hline 7 & Switzerland & 0.29 & 0.45 & $0.3245^{*}$ & $-0.0910^{*}$ & $0.1177^{*}$ & $0.1545^{*}$ & -0.0257 & $-0.6944^{*}$ & & & & & & & \\
\hline 8 & Primary sector & 0.14 & 0.35 & $-0.0984^{*}$ & $-0.1902^{*}$ & $-0.0846^{*}$ & -0.0454 & 0.0189 & $-0.1540^{*}$ & 0.0106 & & & & & & \\
\hline 9 & Secondary Sector & 0.35 & 0.48 & $0.0866^{*}$ & $0.1047^{*}$ & 0.0409 & 0.0189 & 0.0415 & -0.0664 & $0.1584^{*}$ & $-0.3000^{*}$ & & & & & \\
\hline 10 & Earn-out & 0.20 & 0.40 & $0.0867^{*}$ & 0.0334 & 0.0029 & $0.1013^{*}$ & 0.0058 & $-0.1435^{*}$ & $0.1867^{*}$ & -0.0004 & 0.0750 & & & & \\
\hline 11 & Education & 4.02 & 1.23 & 0.0545 & $0.3604^{*}$ & $0.2019^{*}$ & $0.1505^{*}$ & 0.0248 & $0.2005^{*}$ & 0.038 & -0.0455 & 0.0446 & -0.0425 & & & \\
\hline 12 & Professional experience & 12.69 & 8.78 & $0.3040^{*}$ & $-0.0860^{*}$ & 0.0280 & 0.0429 & $-0.3099^{*}$ & $-0.1463^{*}$ & $0.1440^{*}$ & -0.0776 & 0.0452 & 0.0229 & $-0.1213^{*}$ & & \\
\hline 13 & Screening & 3.80 & 2.76 & $-0.0869^{*}$ & $0.2833^{*}$ & 0.0192 & 0.0389 & 0.0254 & $0.2725^{*}$ & 0.0195 & -0.0785 & 0.0125 & 0.0634 & $0.1004^{*}$ & 0.0615 & \\
\hline 14 & Firm age & 62.15 & 48.54 & $-0.2252^{*}$ & 0.0709 & -0.0177 & -0.0068 & $0.0981^{*}$ & 0.0745 & $-0.0918^{*}$ & $0.1971^{*}$ & -0.0678 & -0.0502 & 0.071 & $-0.1054^{*}$ & -0.0553 \\
\hline
\end{tabular}


Table A.2

Logit regression for external versus internal exit routes.

\begin{tabular}{|c|c|c|c|}
\hline & Model 1 & Model 2 & Model 3 \\
\hline Log employees & $-0.232^{*}$ & $-0.233^{*}$ & $-0.211^{*}$ \\
\hline Number of shareholders & $0.113^{*}$ & $0.102^{+}$ & $0.124^{*}$ \\
\hline Number of managing directors & -0.011 & -0.049 & -0.058 \\
\hline Distant takeover & $-0.503^{*}$ & 0.026 & 0.015 \\
\hline Germany & 0.018 & 0.088 & 0.07 \\
\hline Switzerland & $1.459^{* * *}$ & $1.375^{* * *}$ & $1.304^{* * *}$ \\
\hline Primary sector & $-0.968^{* *}$ & -0.507 & -0.373 \\
\hline Secondary sector & 0.100 & 0.093 & 0.146 \\
\hline Earn-out & 0.320 & 0.414 & 0.400 \\
\hline Education & & $0.296^{* *}$ & $0.208^{+}$ \\
\hline Professional experience & & $0.080^{* * *}$ & $0.080^{* * *}$ \\
\hline Screening & & $0.545^{*}$ & $0.585^{*}$ \\
\hline Screening (sq.) & & $-0.140^{* *}$ & $-0.147^{* *}$ \\
\hline Firm age & & $-0.017^{* * *}$ & -0.005 \\
\hline Education $\times$ Firm age & & & $-0.008^{*}$ \\
\hline Prof. experience $\times$ Firm age & & & 0.000 \\
\hline Screening $\times$ Firm age & & & $0.012^{*}$ \\
\hline Screening (sq.) $\times$ Firm age & & & $-0.003^{*}$ \\
\hline Constant & 0.283 & 0.083 & 0.155 \\
\hline Inverse Mills ratio (IMR) & $-0.078^{* *}$ & $-0.072^{* *}$ & $-0.071^{* *}$ \\
\hline $\mathrm{Chi}^{2}$ & 102.501 & 180.380 & 189.305 \\
\hline Prob $>\mathrm{Chi}^{2}$ & 0 & 0 & 0 \\
\hline AIC & $597.145^{* * *}$ & $529.266^{* * *}$ & $528.340^{* * *}$ \\
\hline Observations & 613 & 613 & 613 \\
\hline
\end{tabular}

\section{References}

Aguinis, H., 1995. Statistical power with moderated multiple regression in management research. Journal of Management 21, $1141-1158$.

Aidis, R., Van Praag, M., 2007. Illegal entrepreneurship experience: does it make a difference for business performance and motivation? Journal of Business Venturing 22, 283-310.

Aiken, L.S., West, S.G., 1991. Multiple Regression: Testing and Interpreting Interactions. Sage, Newbury Park, CA.

Akerlof, G.A., 1970. The market for "lemons": quality uncertainty and the market mechanism. Quarterly Journal of Economics 84, 488-500.

Arthurs, J.D., Busenitz, L.W., Hoskisson, R.E., Johnson, R.A., 2009. Signaling and initial public offerings: the use and impact of the lockup period. Journal of Business Venturing 24, 360-372.

Backes-Gellner, U., Werner, A., 2007. Entrepreneurial signaling via education: a success factor in innovative start-ups. Small Business Economics 29, 173-190.

Barach, J.A., Gantisky, J., Carson, J.A., Doochin, B.A., 1988. Entry of the next generation: strategic challenge for family business. Journal of Small Business Management 26, 49-56.

Belk, R.W., 1988. Possessions and the extended self. Journal of Consumer Research 15, 139-168.

Berrone, P., Cruz, C., Gómez-Mejía, L.R., Larraza-Kintana, M., 2010. Socioemotional wealth and corporate responses to institutional pressures: do family-controlled firms pollute less? Administrative Science Quarterly 55, 82-113.

Berrone, P., Cruz, C., Gómez-Mejía, L.R., 2012. Socioemotional wealth in family firms: theoretical dimensions, assessment approaches, and agenda for future research. Family Business Review 25, 258-279.

Birley, S., Westhead, P., 1993. The owner-managers exit route. In: Klandt, H. (Ed.), Entrepreneurship and Business Development. Gower, Avebury.

Bocatto, E., Gispert, C., Rialp, J., 2010. Family-owned business succession: the influence of pre-performance in the nomination of family and nonfamily members: evidence from Spanish firms. Journal of Small Business Management 48, 497-523.

Boyce, R.R., Brown, T.C., McClelland, G.H., Peterson, G.L., Schulze, W.D., 1992. An experimental examination of intrinsic values as a source of the WTA-WTP disparity. American Economic Review 82, 1366-1373.

Burmeister, K., Schade, C., 2007. Are entrepreneurs' decisions more biased? An experimental investigation of the susceptibility to status quo bias. Journal of Business Venturing 22, 340-362.

Capron, L., Shen, J.C., 2007. Acquisitions of private vs. public firms: private information, target selection, and acquirer returns. Strategic Management Journal 28, 891-911.

Cardon, M.S., Zietsma, C., Saparito, P., Matherne, B.P., Davis, C., 2005. A tale of passion: new insights into entrepreneurship from a parenthood metaphor. Journal of Business Venturing 20, 23-45.

Carpentier, C., L'Her, J.-F., Suret, J.-M., 2010. Stock exchange markets for new ventures. Journal of Business Venturing 25, $403-422$.

Carter, N., Brush, C., Greene, P., Gatewood, E., Hart, M., 2003. Women entrepreneurs who break through to equity financing: the influence of human, social and financial capital. Venture Capital: an international journal of entrepreneurial finance 5, 1-28.

Chandler, A.D., 1990. Scale and Scope: The Dynamics of Industrial Capitalism. Belknap Press, Cambridge, MA.

Chang, S.J., Van Witteloostuijn, A., Eden, L., 2010. From the Editors: common method variance in international business research. Journal of International Business Studies 41, 178-184.

Chrisman, J.J., Patel, P., 2012. Variations in R\&D investments of family and non-family firms: behavioral agency and myopic loss aversion perspectives. Academy of Management Journal 55 n/a.

Chrisman, J.J., Chua, J.H., Litz, R.A., 2003. A unified systems perspective of family firm performance: an extension and integration. Journal of Business Venturing 18, $467-472$.

Chrisman, J.J., Chua, J.H., Litz, R.A., 2004. Comparing the agency costs of family and non-family firms: conceptual issues and exploratory evidence. Entrepreneurship Theory and Practice 28, 335-354. 
Chrisman, J.J., Chua, J.H., Kellermanns, F.W., Chang, E.P.C., 2007. Are family managers agents or stewards? An exploratory study in privately held family firms. Journal of Business Research 60, 1030-1038.

Chua, J.H., Chrisman, J.J., Sharma, P., 1999. Defining the family business by behavior. Entrepreneurship Theory and Practice $23,19-39$.

Cohen, B.D., Dean, T.J., 2005. Information asymmetry and investor valuation of IPOs: top management team legitimacy as a capital market signal. Strategic Management Journal 26, 683-690.

Connelly, B.L., Certo, S.T., Ireland, R.D., Reutzel, C.R., 2011. Signaling theory: a review and assessment. Journal of Management $37,39-67$.

Corbetta, G., Salvato, C., 2004. Self-serving or self-actualizing? Models of man and agency costs in different types of family firms: a commentary on "Comparing the agency costs of family and non-family firms: conceptual issues and exploratory evidence". Entrepreneurship Theory and Practice $28,355-362$.

Cruz, C., Justo, R., De Castro, J.O., 2010a. Does family employment enhance MSEs performance?: Integrating socioemotional wealth and family embeddedness perspectives. Journal of Business Venturing.

Cruz, C.C., Gómez-Mejía, L.R., Becerra, M., 2010b. Perceptions of benevolence and the design of agency contracts: CEO-TMT relationships in family firms. Academy of Management Journal 53, 69-89.

Cyert, R.M., March, J.G., 1963. A Behavioral Theory of the Firm, 1st ed. Prentice-Hall, Englewood Cliffs, NJ.

Dalal, D.K., Zickar, M.J., 2012. Some common myths about centering predictor variables in moderated multiple regression and polynomial regression. Organizational Research Methods 15, 339-362.

Dawson, A., 2011. Private equity investment decisions in family firms: the role of human resources and agency costs. Journal of Business Venturing $26,189-199$.

De Massis, A., Chua, J.H., Chrisman, J.J., 2008. Factors preventing intra-family succession. Family Business Review 21, $183-199$.

DeTienne, D.R., 2010. Entrepreneurial exit as a critical component of the entrepreneurial process: theoretical development. Journal of Business Venturing 25, $203-215$.

DeTienne, D.R., Cardon, M., 2012. Impact of founder experience on exit intentions. Small Business Economics 38, 351-374.

DeTienne, D.R., Chandler, G.N., 2010. The impact of motivation and causation and effectuation approaches on exit strategies. Frontiers of Entrepreneurship Research 30,1-13.

Eddleston, K.A., Kellermanns, F.W., Zellweger, T.M., 2012. Exploring the entrepreneurial behavior of family firms: does the stewardship perspective explain differences? Entrepreneurship Theory and Practice 36, 347-367.

Fama, E.F., 1980. Agency problems and the theory of the firm. Journal of Political Economy 88, 288-307.

Farber, H.S., Gibbons, R., 1996. Learning and wage dynamics. Quarterly Journal of Economics 111, 1007-1047.

Folta, T.B., O'Brien, J.P., 2004. Entry in the presence of dueling options. Strategic Management Journal 25, 121-138.

Garen, J.E., 1985. Worker heterogeneity, job screening, and firm size. Journal of Political Economy 93, 715-739.

Gersick, K.E., Davis, J.A., McCollom Hampton, M., Lansberg, I., 1997. Generation to Generation: Life Cycles of the Family Business. Harvard Business School Press, Boston, MA

Gómez-Mejía, L.R., Takács Haynes, K., Núnez-Nickel, M., Jacobson, K.J.L., Moyano-Fuentes, J., 2007. Socioemotional wealth and business risks in family-controlled firms: evidence from Spanish olive oil mills. Administrative Science Quarterly 52, 106-137.

Gómez-Mejía, L.R., Cruz, C., Berrone, P., Castro, J., 2011. The bind that ties: socioemotional wealth preservation in family firms. The Academy of Management Annals 5, 653-707.

Graebner, M.E., 2009. Caveat venditor: trust asymmetries in acquisitions of entrepreneurial firms. Academy of Management Journal 52, $435-472$.

Graebner, M.E., Eisenhardt, K.M., 2004. The seller's side of the story: acquisition as courtship and governance as syndicate in entrepreneurial forms. Administrative Science Quarterly 49, 366-403.

Grayson, K., Shulman, D., 2000. Indexicality and the verification function of irreplaceable possessions: a semiotic analysis. Journal of Consumer Research 17-30.

Hair, J.F., Black, B., Babin, B., Anderson, R.E., Tatham, R.L., 2006. Multivariate Data Analysis, 6th ed. Prentice Hall.

Halter, F., Dehlen, T., Sieger, P., Wolter, H.J. forthcoming. Informationsasymmetrien zwischen Übergeber und Nachfolger: Herausforderungen und Lösungsmöglichkeiten am Beispiel des Management Buy Ins in Familienunternehmen. Zeitschrift für KMU und Entrepreneurship.

Heckman, J.J., 1979. Sample selection bias as a specification error. Econometrica 47, 153-161.

Hitt, M.A., Tyler, B.B., 1991. Strategic decision models: integrating different perspectives. Strategic Management Journal 12, $327-351$.

Hoetker, G., 2007. The use of logit and probit models in strategic management research: critical issues. Strategic Management Journal 28, $331-343$.

Holmstrom, B., 1982. Managerial Incentive Problems - A Dynamic Perspective. Essays in Economics and Management in Honor of Lars Wahlbeck. Swedish School of Economics, pp. 209-230.

Howorth, C., Westhead, P., Wright, M., 2004. Buyouts, information asymmetry and the family management dyad. Journal of Business Venturing $19,509-534$.

Jain, B.A., Tabak, F., 2008. Factors influencing the choice between founder versus non-founder CEOs for IPO firms. Journal of Business Venturing $23,21-45$.

Janney, J.J., Folta, T.B., 2003. Signaling through private equity placements and its impact on the valuation of biotechnology firms. Journal of Business Venturing 18 , 361-380.

Janney, J.J., Folta, T.B., 2006. Moderating effects of investor experience on the signaling value of private equity placements. Journal of Business Venturing 21, 27-44.

Jensen, M.C., 1986. Agency costs of free cash flow, corporate finance, and takeovers. American Economic Review 76, $323-329$.

Jiang, C.X., Zimmerman, M.A., Guo, G.C., 2012. Growth of women-owned businesses: the effects of intangible resources and social competence. Journal of business Diversity $12,47-71$.

Justo, R., DeTienne, D.R., 2008. Family situation and the exit event: an extension of threshold theory. Frontiers of Entrepreneurship Research 28, 1-13.

Kahneman, D., Tversky, A., 1979. Prospect theory: an analysis of decision under risk. Econometrica 47, $263-291$.

Kellermanns, F.W., Eddleston, K., Barnett, T., Pearson, A.W., 2008. An exploratory study of family member characteristics and involvement: effects on entrepreneurial behavior in the family firm. Family Business Review 21, 1-14.

Kim, P.H., Aldrich, H.E., Keister, L.A., 2006. Access (not) denied: the impact of financial, human, and cultural capital on entrepreneurial entry in the United States. Small Business Economics 27, 5-22.

Knetsch, J.L., 1989. The endowment effect and evidence of nonreversible indifference curves. American Economic Review 79, $1277-1284$.

Koenig, A., Kammerlander, N., Enders, A. The family innovator's dilemma: how family influence affects the adoption of discontinuous technologies by incumbent firms. Academy of Management Review, forthcoming.

Kreps, D.M., 1997. Intrinsic motivation and extrinsic incentives. American Economic Review 87, 359-364.

Kumar, N., Stern, L.W., Anderson, J.C., 1993. Conducting interorganizational research using key in-formants. Academy of Management Journal 36, $1633-1651$.

Le Breton-Miller, I., Miller, D., Steier, L.P., 2004. Toward an integrative model of effective FOB succession. Entrepreneurship Theory \& Practice 28, 305-328.

Lee, J.-H., Venkataraman, S., 2006. Aspirations, market offerings, and the pursuit of entrepreneurial opportunities. Journal of Business Venturing $21,107-123$.

Lee, K.S., Lim, G.H., Lim, W.S., 2003. Family business succession: appropriation risk and choice of successor. Academy of Management Review 28, $657-666$.

Li, J.T., Tang, Y., 2010. CEO hubris and firm risk taking in China: the moderating role of managerial discretion. Academy of Management Journal 53, 45-68.

Long, S., Freese, J., 2005. Regression Models for Categorical Dependent Variables using Stata. Stata Press.

Lord, C.G., Ross, L., Lepper, M.R., 1979. Biased assimilation and attitude polarization: the effects of prior theories on subsequently considered evidence. Journal of Personality and Social Psychology 37, 2098.

Mas-Colell, A., Whinston, M.D., Green, J.R., 1995. Microeconomic Theory. Oxford University Press, New York City, New York.

Mishina, Y., Dykes, B.J., Block, E.S., Pollock, T.G., 2010. Why "good" firms do bad things: the effects of high aspirations, high expectations, and prominence on the incidence of corporate illegality. Academy of Management Journal 53, 701-722.

Morris, M.H., Williams, R.O., 1997. Correlates of success in family business transitions. Journal of Business Venturing $12,385-401$.

Niedermeyer, C., Jaskiewicz, P., Klein, S.B., 2010. 'Can't get no satisfaction?' Evaluating the sale of the family business from the family's perspective and deriving implications for new venture activities. Entrepreneurship and Regional Development 22, 293-320.

Oppenheim, A.N., 1966. Questionnaire Design and Attitude Measurement. Free Press, New York. 
Palfrey, T.R., Spatt, C.S., 1985. Repeated insurance contracts and learning. The Rand Journal of Economics 16, $356-367$.

Parker, S.C., Van Praag, C.M., 2012. The entrepreneur's mode of entry: business takeover or new venture start? Journal of Business Venturing 27, 31-46.

Petty, J., 1997. Harvesting firm value: process and results. In: Sexton, D.L., Smilor, R.W. (Eds.), Entrepreneurship 2000. Upstart, Chicago.

Podsakoff, P.M., Organ, D.W., 1986. Self-reports in organizational research: problems and perspectives. Journal of Management 12, 531-544.

Podsakoff, P.M., MacKenzie, S.B., Lee, J.-Y., Podsakoff, N.P., 2003. Common method biases in behavioral research: a critical review of the literature and recommended remedies. Journal of Applied Psychology 88, 879-903.

Reuber, A.R., Fischer, E.M., 1994. Entrepreneurs' experience, expertise, and the performance of technology-based firms. IEEE Transactions on Engineering Management 41, 365-374.

Riley, J.G., 1979. Testing the educational screening hypothesis. Journal of Political Economy 87, S227-S252.

Royer, S., Simons, R., Boyd, B., Rafferty, A., 2008. Promoting family: a contingency model of family business succession. Family Business Review 21, 15-30.

Rubin, D.B., 1987. Multiple Imputation for Nonresponse in Surveys. Wiley Online Library.

Salvato, C., Chirico, F., Sharma, P., 2010. A farewell to the business: championing exit and continuity in entrepreneurial family firms. Entrepreneurship and Regional Development 22, 321-348.

Schafer, J.L., 1999. Multiple imputation: a primer. Statistical Methods in Medical Research 8, 3-15.

Schafer, J.L., Graham, J.W., 2002. Missing data: our view of the state of the art. Psychological Methods 7, $147-177$.

Scholes, L., Wright, M., Westhead, P., Burrows, A., Bruining, H., 2007. Information sharing, price negotiation and management buy-outs of private family-owned firms. Small Business Economics 29.

Scholes, L., Westhead, P., Burrows, A., 2008. Family firm succession: the management buy-out and buy-in routes. Journal of Small Business and Enterprise Development 15, 8-29.

Schulze, W.S., Lubatkin, M.H., Dino, R.N., Buchholtz, A.K., 2001. Agency relationships in family firms: theory and evidence. Organization Science 12, 99-116.

Seidler, J., 1974. On using key informants: a technique for collecting quantitative data and controlling measurement error in organization analysis. American Sociological Review 39, 816-831.

Sharma, P., Manikutty, S., 2005. Strategic divestments in family firms: role of family structure and community culture. Entrepreneurship Theory and Practice 29, 293-311.

Sharma, P., Chrisman, J.J., Chua, J.H., 2003. Predictors of satisfaction with the succession process in family firms. Journal of Business Venturing 18 , 667-687.

Sharma, P., Chrisman, J.J., Gersick, K.E., 2012. 25 years of family business review: reflections on the past and perspectives for the future. Family Business Review 25, 5-15.

Spence, M., 1973. Job market signaling. Quarterly Journal of Economics 87, 355-374.

Spence, M., 1976. Informational aspects of market structure: an introduction. Quarterly Journal of Economics 90, 591-597.

Sternberg, L., Lückgen, I., 2005. Global Entrepreneurship - German Report . Cologne, Germany.

Stiglitz, J.E., 1975. The theory of "screening," education, and the distribution of income. The American Economic Review 65, $283-300$.

Stiglitz, J.E., 1977. Symposium on economics of information: introduction. Review of Economic Studies 44, 389-391.

Stiglitz, J.E., 2000. The contributions of the economics of information to twentieth century economics. Quarterly Journal of Economics $115,1441-1478$.

Tabachnick, B.G., Fidell, L.S., 1996. Using Multivariate Statistics, 3rd ed. HarperCollins College Publishers, New York.

Tourangeau, R., Rips, L.J., Rasinski, K., 2000. The Psychology of Survey Response. Cambridge University Press, Cambridge, England.

Unger, J.M., Keith, N., Hilling, C., Gielnik, M.M., Frese, M., 2009. Deliberate practice among South African small business owners: relationships with education, cognitive ability, knowledge, and success. Journal of Occupational and Organizational Psychology 82, 21-44.

Unger, J.M., Rauch, A., Frese, M., Rosenbusch, N., 2011. Human capital and entrepreneurial success: a meta-analytical review. Journal of Business Venturing 26, $341-358$.

Volery, T., Bergmann, H., Gruber, M., Haour, G., Leleux, B., 2007. Global Entrepreneurship Monitor - Swiss Report. St. Gallen, Switzerland.

Ward, J.L., 1987. Keeping the Family Business Healthy. Jossey-Bass, San Francisco, CA.

Wennberg, K., Wiklund, J., DeTienne, D.R., Cardon, M.S., 2010. Reconceptualizing entrepreneurial exit: divergent exit routes and their drivers. Journal of Business Venturing 25, 361-375.

Wennberg, K., Wiklund, J., Hellerstedt, K., Nordqvist, M., 2011. Implications of intra-family and external ownership transfer of family firms: short-term and long-term performance differences. Strategic Entrepreneurship Journal 5, 352-372.

Westhead, P., 2003. Succession decision-making outcomes reported by private family companies. International Small Business Journal $21,369-401$.

Westphal, J.D., Zajac, E.J., 1995. Who shall govern? CEO/board power, demographic similarity, and new director selection. Administrative Science Quarterly 40, 60-83.

Wiersema, M.F., Bantel, K.A., 1992. Top management team demography and corporate strategic change. Academy of Management Journal 35, 91-121.

Wiersema, M.F., Bowen, H.P., 2009. The use of limited dependent variable techniques in strategy research: issues and methods. Strategic Management Journal 30, 679-692.

Wiseman, R.M., Gómez-Mejía, L.R., 1998. A behavioral agency model of managerial risk taking. Academy of Management Review $23,133-153$.

Zajac, E.J., 1990. CEO selection, succession, compensation and firm performance: a theoretical integration and empirical analysis. Strategic Management Journal $11,217-230$.

Zellweger, T.M., Kellermanns, F.W., Chrisman, J.J., Chua, J.H., 2012. Family control and family firm valuations by family CEOs: the importance of intentions for transgenerational control. Organization Science 23, 851-868.

Zelner, B.A., 2009. Using simulation to interpret results from logit, probit, and other nonlinear models. Strategic Management Journal 30, $1335-1348$.

Zhang, Y., 2008. Information asymmetry and the dismissal of newly appointed CEOs: an empirical investigation. Strategic Management Journal 29, 859-872.

Zhang, Y., Wiersema, M.F., 2009. Stock market reaction to CEO certification: the signaling role of CEO background. Strategic Management Journal 30, 693-710. 